\title{
CHILDREN WITH RHEUMATIC DISEASES AND/OR USING IMMUNOSUPPRESSIVE AGENTS AND COVID-19: IS THIS A REAL CONCERN?
}

Juliana Russo Simon ${ }^{1}$, Maria Fernanda Badue Pereira ${ }^{1}$, Heloisa Helena de Souza Marques ${ }^{1}$, Bianca Pires Ihara ${ }^{1}$, Reinan Tavares Campos $^{1}$, Claudia Alejandra Ayala Strabelli1 ${ }^{1}$ Katia Tomie Kozu¹, Nádia Emi Aikawa ${ }^{1}$, Adriana Maluf Elias ${ }^{1}$, Juliana Caires Achili Ferreira ${ }^{1}$, Neusa Keiko Sakita ${ }^{1}$, Thais de Toledo Fink ${ }^{1}$, Priscila da Silveira Suguita ${ }^{1}$, Vera Bain ${ }^{1}$, Clovis Artur Almeida da Silva ${ }^{1}$, Lucia Maria de Arruda Campos ${ }^{1, *}$

1. Hospital das Clínicas HCFMUSP, Universidade de São Paulo, São Paulo (SP), Brazil.

*Corresponding author: julianarussosimon@gmail.com

\section{BACKGROUND}

Coronavirus-19 disease (COVID-19) has been poorly studied in immunosuppressed pediatric population, even less in children with rheumatic diseases. This study aims to study the frequency of asymptomatic severe acute respiratory syndrome coronavirus 2 (SARS-CoV-2) infection in children with rheumatic diseases and to identify the risk factors related to contagion.

\section{METHODS}

This is a cross-sectional study performed with 77 patients followed at the pediatric rheumatology unit of a Brazilian tertiary hospital and 45 healthy controls (ages 1-19 years), conducted on March 2021. Patients and controls answered a questionnaire with demographic data, symptoms compatible with COVID-19 over the past year, contact with people with confirmed COVID-19, and contact with other immunosuppressed individuals in their residence. Patients' medical records were reviewed to obtain data regarding disease, current medications and their doses. A qualitative immunochromatographic test was performed in all participants.

\section{RESULTS}

SARS-CoV-2 serology positivity was similar in patients and controls ( $22 \% \mathrm{vs.} 15.5 \%, p=0.481$ ) and the groups were comparable regarding female gender ( $70.1 \%$ vs. $57.8 \%, p=0.173)$ and current age ( 14 vs. 13 years, $p=0.269)$. Patients presented lower median family income ( 2.5 vs 5 minimum wages, $p<0.001$ ) and median years of maternal education ( 11 vs. 14 years, $p=0.002$ ). Contact with SARS-CoV-2 occurred in their own homes in patients and controls ( $76.5 \%$ vs. $88.2 \%, p=0.656)$. A total of $80.5 \%$ of patients with rheumatic disease were in use of immunosuppressive drugs, $27.3 \%$ of them were using corticosteroids, $33.3 \%$ in high doses (> $20 \mathrm{mg} /$ day or $1 \mathrm{mg} / \mathrm{kg} / \mathrm{day}$ ); $7.8 \%$ of patients were on immunobiologicals. The patients were divided in two groups: positive $(n=17)$ and negative serology $(n=60)$. No statistical differences were found between the groups regarding demographic and socioeconomic data, contact with people with confirmed COVID-19 or with other immunocompromised individuals. Regarding treatment, the groups were similar in terms of use and number of immunosuppressive drugs, use and dose of corticosteroids, use of hydroxychloroquine and immunobiological drugs, independently of the underlying disease.

\section{CONCLUSION}

Children with rheumatic disease were infected at the same rate as healthy ones, independently of demographic and socioeconomical data. Furthermore, neither the type of underlying pathology nor its treatment seemed to interfere with the risk of contagion, which occurred mostly within their own residence. Larger and multicenter studies are needed to corroborate these results and, thus, formally free us from the concern to allow children and adolescents with rheumatologic disease to resume their daily activities and socialization.

\section{KEYWORDS}

Children with rheumatic diseases, Immunosuppressive agents, COVID-19, SARS-CoV-2, Asymptomatic infection. 